\title{
Post-disaster recovery: the challenge of anticipation
}

\author{
Annabelle Moatty ${ }^{1, a}$ and Freddy Vinet ${ }^{1}$ \\ ${ }^{1}$ University Paul Valéry - Montpellier III, Joint Research Unit GRED (Governance Risk Environment and Development)
}

\begin{abstract}
The recurrence of disasters, sometimes in the same territories, questioned the effectiveness of the preventive logic and of the post-disaster recovery process. The present reconstruction approach aims at analysing the interactions between risk, societies and territories. The study of the recovery process in a holistic way through a medium and long-term feedback defines its operating rules, and its "good and bad practices" regarding the objectives of risk reduction and sustainable development. The lack of anticipation, the numerous uncertainties and the emergency in which the decisions are taken, lead in many cases, to risk persistence and increased social gaps. When "preventive ethics" is integrated into the process, it remains occasional and marginal. Reconstruction does not start from a "zero state"; it is subjected to territorial, economic and political constraints. Thus, in order to make the postdisaster reconstruction a preventive opportunity, an anticipatory effort is needed - though necessarily limited - it must be accompanied by an ex-post planning. These considerations will be illustrated by the examples of the recovery of two French departments: the Aude department after the $12^{\text {th }}$ and $13^{\text {th }}$ November 1999 floods, and the Var department after the $15^{\text {th }}$ and $16^{\text {th }}$ June 2010 floods.
\end{abstract}

\section{Introduction}

Each year, 250 million people on average are affected by disasters [1]. If disasters and immediate post-crisis periods are high profile, recovery is not subjected to so much attention. However, the recovery process mobilises considerable funds and energy in the long term, ranging from three to twenty years. Despite the resources mobilised and sometimes the clearly stated wishes of a move towards more risk prevention, recurrence of recent catastrophic events and the surges of solidarity which accompanied them raised the difficult question of post-disaster recovery.

Research on recovery highlights the potential of this period in reducing vulnerability [2, 3, 4, 5]. Yet experience demonstrates that in many cases postdisaster is digging inequalities and is a period of accelerating existing trends $[4,6,7]$. Therefore, the challenge is how to maximise the potential of this period? Pitfalls can be identified upstream and, locally, levers exist to facilitate the integration of "preventive ethics". "Preventive ethics" imply a set of measures for the inclusion of the disaster reduction in the recovery, the compliance with preventive construction standards and the establishment of ex-ante management in order to prepare to respond to a future disaster, in a multi-hazard and systemic approach, otherwise the effectiveness of these measures can be compromised when the project is implemented.
Examples of reconstruction in the Aude department after the floods of $12^{\text {th }}$ and $13^{\text {th }}$ November 1999 and in the Var after those of $15^{\text {th }}$ and $16^{\text {th }}$ June 2010 will illustrate this. The watershed of the Aude was severely affected by flooding in November 1999 leaving 25 dead and more than 413 million euros of damage. The reconstruction effort was living up to the extent of damage: present on a large part of the departmental territory, impacting all the activities, and all the sectors of society, from public to private property through companies and farms. The greater part of the reconstruction and rehabilitation operations were carried out in the four years after the disaster, but some cases dragged on for over 10 years.

In the Var department, on $15^{\text {th }}$ and $16^{\text {th }}$ June 2010, heavy rainfall affected the Dracénie area. The flood impacted a small part of the territory where many assets are concentrated. Damages amounted to 1.2 billion euros. The following years other flood events affected the area, delaying and complicating the recovery after June 2010.

Data were collected through social science surveys, document analysis, working in archives and field observations. The feedback method was adapted to the needs and constraints of a medium and long term analysis. The implementation phase of the investigations took place during 2014. In total, 58 people (32 in the Aude and 26 in the Var)

\footnotetext{
${ }^{\mathrm{a}}$ Corresponding author: amoatty@yahoo.fr
} 
were subjects of the survey through semi-structured interviews (the duration ranged from one hour and a half to six hours). One single interview grid was made and adapted regarding the missions of the stakeholders and their involvement in the various stages of the process. The data collected was subjected to a qualitative and quantitative treatment.

This article aims to analyse the conditions for the implementation of an anticipation strategy of recovery process, as well as its strengths and limitations. To analyse the different elements which compose the proactive approach and the main "good practices" and pitfalls of the process, this article initially describes the concept of reconstruction as a "window of opportunity", secondly, it addresses anticipation as a lever to develop "preventive ethics", and third$1 \mathrm{y}$, it will complete by the complementarity of the ex-ante and ex-post approaches of recovery, a period which is an in-between: between ruptures and continuities.

\section{Recovery as a "window of op- portunity"}

\subsection{The "window of opportunity" approach or the need for a paradigm shift}

As disasters generate the need to rebuild, they can be used as a support to review biases of obsolete or unsuitable land-use strategies and more widely on development policies. Recovery can be a "window of opportunity" [3] because it is a time when local stakeholders gather around a common goal: managing the recovery of society. The damage and destruction open the possibility of rebuilding otherwise. Nevertheless, in spite of the good will spread in all layers of society and the vulnerability awareness generated by the disaster, the implementation of "preventive ethics" is not obvious and faces many obstacles.

This period sets up "favourable conditions" for a decompartmentalisation of the sectors and categories of stakeholders who are not used to working together because of the theoretical barrier that segregates the different fields of land-use management. The way the funds allocated to recovery are distributed is a major issue for integrating Disaster Risk Reduction measures (DRR) in the recovery process. But, within the contexts of precipitation in which decisions are taken and facing the will to purchase "social peace" in a strained context (where the existing conflicts are reactivated or exacerbated), those funds are often misused.

Considering the recovery period as a "window of opportunity" involves defining the characteristics of a "good recovery". It is here understood as an effective recovery in terms of risk reduction, of decreasing the socio-economic and territorial disparities, which must be integrated into existing programs. It must also be viewed as a moment of the life of society with the objective of meeting the needs of the stakeholders at different spatial (from national to local, including population) and temporal scales (from short to long term) by dealing with specific time constraints of the recovery and with the ones of the other processes (development, prevention, etc.).

Anticipating post-disaster itself, is not evident as it means foreseeing massive destructions that will more or less permanently disrupt the system, and at the same time imagine and prepare potential desirable responses. This implies the necessity of a paradigm shift: disasters will reoccur in the future but their occurrence terms are uncertain. Post-disaster planning documents already exist, such as the Disaster Mitigation Act [8] of 2000 in the United States. This planning document for crisis and recovery management operations is based on the nuclear threat model. The very existence of such a document emphasises the need to be prepared to cope with and to respond in order to reorganise [9]. Thus the anticipation of the post-disaster requires a paradigm shift but also accompanies it, i.e. it can be a way to make it operational.

\subsection{The difficulties of establishing preventive ethics}

Many obstacles are raised against the establishment of "preventive ethics", and most of the time, the easiest way of rebuilding as close as possible as it was before is the rule.

The specific temporality of the recovery process can be one of these obstacles. In the early stages of the process, the recovery is marked by a period of "time compression" when the activities and decisions [10] have to be taken quickly in order to avoid the precarious situations to drag too long and to allow the victims to re-start living in dignified conditions. Many of the interviewed stakeholders are likely to evoke the paradox between, on the one hand the rapid mobilisation and response, and on the other hand a kind of torpor facing the extent of the reconstruction task. The reporting dates of the Natural Disaster Declaration in France illustrate this rapid responsiveness (4 days in the Aude and in the Var).

In the Aude department, as it was in the Var (and as is the case almost systematically in France), there are emergency procedures to release funds quickly and begin to repair and rehabilitate as soon as possible. These procedures are effective for a period of three months during which damages are assessed, the victims are rehoused (on a temporary basis) and the first funds are paid. They support, and therefore facilitate, the myriad of decisions and actions that had to be taken simultaneously and quickly. However, for $88 \%$ of respondents from the two departments, this period of regulations and procedures relief proved to be too short. "Three months is too short, we barely had time 
to realise what was happening to us and what was needed to start living again. And then, we just had time to assess the damage, the proper procedures were no longer a possible solution because we had exceeded the period of three months" (interview with a local representative, Aude department, 2014). Once this period of time has elapsed, standard procedures come into play. These drag on the funds programming, but also on the precarious situations that were meant to be temporary. This was the case for some households in the Var department who were rehoused in mobile homes for 2 to 3 years (interview with an anonymous respondent in Var, 2014). Their houses were completely destroyed and for a few of them, the plot narrowed considerably because of erosion. The government decided to relocate them, and meanwhile they were sheltered in mobile homes.

Overall, the recovery period extends over ten years with a concentration of reconstruction operations in the first four years. In the Aude department, on $12^{\text {th }}$ November 2002, for the third anniversary of the devastating floods, a closing ceremony of reconstruction efforts was organised, but some cases have dragged on longer. This was the case for the dikes of Cuxac-d'Aude. The situation was complex and expensive as it required buying about thirty houses. In January 2008 the first house negotiating buyouts began thanks to the Prevention of Major Natural Risks Fund $\left(\mathrm{FPRNM}^{1}\right)$ and the dike was inaugurated in December 2014, 15 years after the flood.

"Temporal dilution" of recovery operations in land-use planning can be mentioned. The construction of the dike contributes to restructure the relationship of the society to the risk by changing its nature (the dike should prevent the high to medium frequency events, but creates a risk of rupture in case of extreme flood). Insofar as the project was developed in response to the 1999 floods it fits into the reconstruction process and this duration is in line with the finding that the indirect effects of the disaster and the choices made during recovery can last over decades.

Apart from this emergency period, procedures are not adapted to the needs created by the reconstruction. This is particularly true for funding. "The risk prevention policy and the compensation of natural disasters are juxtaposed but they largely ignore each other" [11]. The contradictions between the principles of intervention of the Water Agency and the nature of the actions they had financed (on request of the State) during the reconstruction reflected this point.

These contradictions can be partly explained by the pressure of the elected officials upon funders and

${ }^{1}$ The FPRNM is powered by a surcharge of $12 \%$ on home insurance policies paid by all insured French households. This fund allows the repurchasing of dwellings that are too exposed to risks to preserve the lives of its occupants. It also provides funding for vulnerability reduction efforts if the municipality has a Risk Prevention Plan (PPR). project owners. The officials themselves are under pressure from the victims and companies who want to rebuild as fast as possible. In the Aude department, in the municipality of Cabrespine, the Wastewater Treatment Plant (WWTP) was partially destroyed and during its reconstruction the focus was put on securing the installation at lower cost and for medium risk. Concrete protections were built in the river bed, to the detriment of its long-term protection and protection of the environment. This choice contributes to weakening the discourse of institutional stakeholders for the elected officials [5]. The Mayor of Cabrespine had been asking for this kind of protection for several years. The project had been refused evoking the Water Law (which forbids that kind of construction), before finally being accepted during reconstruction.

The issue of WWTP is emblematic. Indeed when damaged, it is impossible to leave it unchanged. During the time necessary for the studies (environmental impact, and efficiency in term of DRR regarding investment costs), the wastewater would go straight into the environment, causing considerable pollution. Because of the lack of anticipation, WWTP are rebuilt on site and as it was before, since for this type of assets, post-disaster is not the time for studies. It also applies to other issues that may be described as strategic like the bridges and roads for which it is difficult to compel or prohibit their use over long periods.

In addition, funding programs focus on the short term and are not suited for the long temporality of post-disaster recovery. Moreover, the regulations that govern the use of public funds may constrain adaptation strategies that necessarily take time, yet they also guarantee the fulfilling of rules ensuring a minimal level of control. This is especially true for resettlement issues that require time, especially in configurations of delocalisation and relocation.

This was the case in Cuxac-d'Aude for example, where the Prevention Plan for Flood Risk (PPRI) had commissioned the construction of a 20sqm refuge shelter above the first floor for all the houses located behind the dike. Several obstacles stand facing the implementation of this measure. The PPRI was finally approved in November 2008, 9 years after the disaster, while all the houses have been restored and reconstructed. As this measure is made mandatory, it becomes fundable by the FPRNM. But despite this grant some households still cannot afford to pay for such building work. The law provides that aid of the National Housing Agency (ANAH) can be mobilised to complete the FPRNM subsidies, but people's incomes were too high to be eligible. These households whose houses are now located behind the dike are in an in-between: too poor to pay the subsidised and too rich to qualify for additional aid.

This type of situation can be anticipated and thus avoid wasting time and money. The inclusion of the measure in the regulatory and legislative documents before the disaster, and the ex-ante development of the 
administrative and financial arrangements to remove the upper limit for ANAH's aid for a limited period from the date of publication of the Natural Disaster Declaration for example, would increase the rate of realisation of this type of heavy building work that is likely to save lives.

\subsection{The difficult redevelopment of a village after floods: the case of Durban-Corbières in the Aude department}

The example of Durban-Corbières illustrates the difficult redevelopment of a village after torrential floods. Before the 1999 floods, the urbanisation of the village had expanded towards the banks of the Berre River (see figure 1). The installation of population and activities in this prone area was permitted partly by the lack of flood experienced by the south of France between 1970 and 1990, which helped forget about the risk. [5].

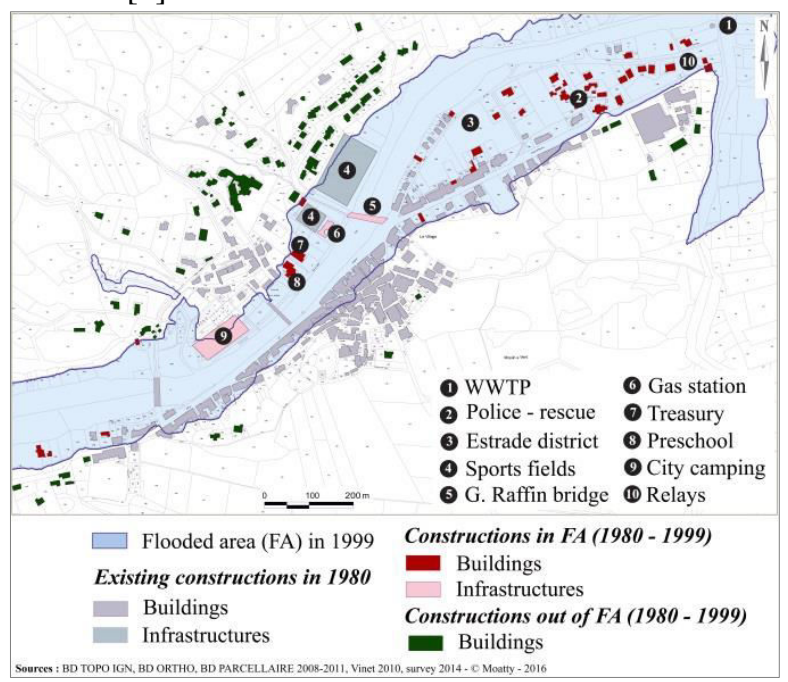

Figure 1: Development of Durban-Corbières before the November 1999 floods

The decision was taken to rebuild differently by restructuring the village's territory in a less vulnerable and less exposed way. By 2000, the Estrade district was converted into flood expansion zone (see figure 2 ). The FPRNM could not be used due to the lack of PPRI in the municipality (approved in 2006). It was therefore necessary to imagine administrative and financial arrangements to achieve these relocations quickly and to this purpose, the slum clearance law was convened.

The houses located in the Estrade district were thus freed from their occupants, as well as garages at the riverbank (see figure 2 ). The police and rescue centre were moved to the grounds of the former wine cooperative now demolished after decommissioning. The preschool, the treasury and the city campsite were rebuilt outside of the hazard prone area. This redistribution of services and housing questioned the coherence of the village. The Relays (see figure 2) should be razed to widen the river bed and create gentle slopes. They are currently not demolished because a craftsman refused to leave. The municipality now reuses these buildings as storage rooms and meeting place for organisations.

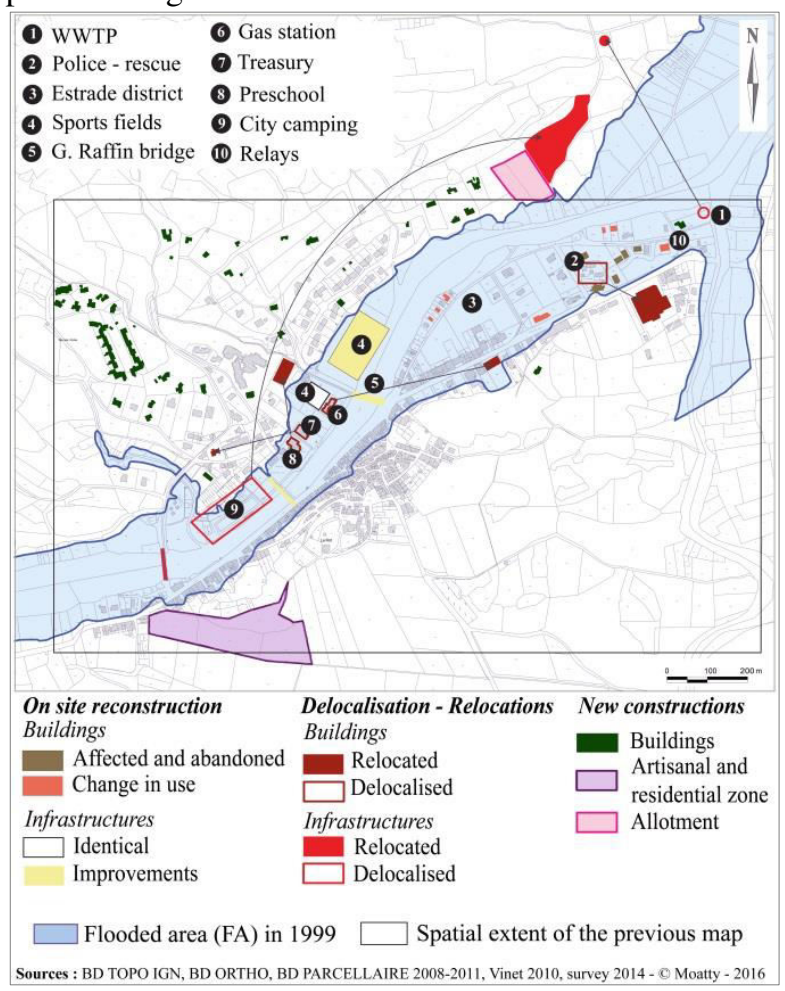

Figure 2: Reconstruction and development of DurbanCorbières following the November 1999 floods

The example of Durban-Corbières proves that it is possible to stop development in flood areas by active and strong-willed policies. The redeployment out of the hazard prone area is complex but effective (see figure 2). However, if relocations are emblematic, they remain at the margin. On the riverbanks, the houses were also affected but the relocation from old and adjoining buildings is complicated because that would have meant buying all the houses on the waterfront. No measure of risk reduction, or adaptation, was taken because of the considerable additional costs associated to the age of the buildings and their adjoining configuration of cohousing.

This example illustrates a case of "adaptive reconstruction" in the sense where the territory was recomposed including DRR measures which were implemented during recovery and which would not have been possible without the occurrence of the disaster of 1999, and of the following floods in 2005 and 2006. Proactive measures are possible under certain conditions, but they require a lot of energy and resources for rather marginal preventive results. 


\section{Anticipation as a lever for the implementation of "preventive ethics" during the recovery}

\subsection{The main objectives of anticipation}

To "break the vicious circle of vulnerability for engaging the virtuous circles of growth and development" [12], optimisation of the recovery process can be a key element. This optimisation involves that the anticipation effort must answer the following questions (see table 1):

\begin{tabular}{|c|c|c|}
\hline \multirow{14}{*}{ 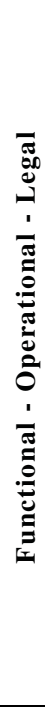 } & \multirow{4}{*}{ Who? } & Which stakeholders must be integrated? \\
\hline & & What skills are required? \\
\hline & & How can stakeholders cooperate? \\
\hline & & $\begin{array}{l}\text { What is the legitimacy of the stakehold- } \\
\text { ers? }\end{array}$ \\
\hline & \multirow{7}{*}{ How? } & $\begin{array}{l}\text { What financial and human resources are } \\
\text { available locally? }\end{array}$ \\
\hline & & $\begin{array}{l}\text { What are the needs in external finan- } \\
\text { cial and human resources? }\end{array}$ \\
\hline & & $\begin{array}{l}\text { How to embed civil society in the pro- } \\
\text { cess? }\end{array}$ \\
\hline & & $\begin{array}{l}\text { What are the support and monitoring } \\
\text { procedures that should be enabled? }\end{array}$ \\
\hline & & What building standards are to be used? \\
\hline & & What redistribution of wealth? \\
\hline & & What is the mitigation frame? \\
\hline & \multirow{3}{*}{ Where? } & What type of territorial recomposition? \\
\hline & & What assets should be relocated? \\
\hline & & Where should they be relocated? \\
\hline
\end{tabular}

Table 1: Issues to be addressed to create anticipatory strategy

The key elements of a reconstruction policy can be grouped into three categories. The first category is functional and consists in establishing an institutional framework for the implementation of the recovery strategy. To reach that purpose, stakeholders need to identify the roles and responsibilities of each organisation in all territorial scales and define mechanisms of coordination and cooperation (see table 1). The second category is operational, and it is the extension of the first point. The aim is to establish a framework for the participation of civil society in the anticipation and implementation of the recovery program. The third category is legal and regulatory. The goal is to create financial, administrative and regulatory packages to adapt the existing framework to the specificities of the recovery mainly in the context of a complicated decision-making, marked by multiple uncertainties and a need for speed.

This preparatory work aims at addressing the three challenges of recovery. The first one is to quickly restore daily activities and living conditions, the second one is to protect society against future dangers, in particular the "domino effects", and the third one is to build the conditions to achieve collective goals, notably through the recomposition of the territory [2]. This restructuring must be conducted in order to facilitate the integration of DRR measures.
To be operational, the strategy must be translated into action plans in four operational territorial levels. The national level, which reflects its strategy through a set of standards and codes implemented in a regional and municipal development plan, completed by neighbourhood or specific sites plans [2].

In this exercise, the complexity lies in the variety of possible interactions - characterised by a high degree of uncertainty - between resources, threats and solutions. To answer this wide range of possible situations, the strategy must consist of a set of alternative plans, resources, rules and procedures. Each sub-plan contains its own resource requirements, its activation and ending procedures, its own temporal objectives of reconstruction and its own rehabilitation profile. In addition to the abovementioned objectives, the choice of a strategy is conditioned by conjuncture factors in particular economic, legal and available resources limits.

The first step of translating a strategy into a subplan involves the national assessment of planning needs. It must be followed by the implementation of feedback in order to fit the local conditions, which is the second step. The third one is the use of science in strategic and operational documents. These inputs must feed an effort to assess the effectiveness of public policies; it is the fourth step [13]. The last step is to create a sustainable recovery policy at the national level. This fifth stage operates the feeding information back, thus combining the "top-down" and "bottom-up" approaches. However, the reconstruction strategy cannot be infallible because it depends on the stakeholder network implementing it.

The interest of reconstruction planning is to accelerate the response, to increase its effectiveness in terms of DRR and sustainable development and reduce inconsistencies. To cope with it, integrating recovery process into existing strategies is a necessity. In France (as it can also be the case in other countries) legislative and regulatory documents relating to the management of natural hazards are numerous (Town Planning Code, the Environment Code, Code of local authorities, etc.) and the purpose here is not to propose the creation of a redundant document - with a risk of being contradictory - with others, but instead, using existing documents and completing them to make them integrate the principles of DRR in postdisaster reconstruction. To that purpose, defining $e x$ ante mandatory measures and creating an organisation to monitor the implementation is a necessity.

Ultimately the goal of this anticipation effort is to define the "enabling conditions" for the establishment of a reconstruction process that incorporates both the "preventive ethics" and sustainability. The path bifurcations operated in post-disaster period are easier to implement if designed ex-ante by a reflection on collective goals in order to withstand the test of "time stress" and "temporal dilution" characterising the recovery period. 


\subsection{Prerequisites to the anticipation of the recovery process}

The first step of an anticipatory strategy regarding integration of hazards in the reconstruction is composed of the identification, description and assessment of risks [2, 14]. Standardised but adaptive grids for ex-ante risk assessment and for ex-post damages assessment must be made available for managers to avoid deadweight effect and to save time. Additional$1 y$, in the perspective of evaluating the effectiveness of the recovery plans, standardisation of data collection would allow centralised processing to compare the reconstructions with similar characteristics.

When there is no standardised method, the accuracy of damage assessment often depends on the acquaintance of the agent with the claimant. Indeed, the Aude department has "benefited" from the reconstruction to implement the upgraded policy of equipment and infrastructure. This opportunistic approach is a particular case, not only due to the occurrence of floods in November 1999 but more because of a favourable local political situation that was activated after the flood. The primary objective of upgrading public facilities was not to reduce vulnerability although it could contribute to modernising antiquated goods.

The second step is the definition of objectives in terms of continuity, recomposition and mitigation. They must be declined in action plans which should specify the essential measures to ensure the local recovery. The objective is to define a loss limit that society can suffer without abandoning its development outlooks. Those elements are preparing the anticipation of societies' recovery and the recomposition of the territory. For example, it will allow to define the terms and conditions of mitigation for housing through appropriate construction techniques, or through relocation when protection costs are too high.

Indeed, the hazard zoning associated with scenarios and feasibility studies (technical and financial) of mitigating measures will condition a different type of zoning: the areas to relocate. In terms of anticipation rehousing areas (first temporary and then permanent) there are three core objectives. The first one is to maintain a standard of living by the proximity of livelihoods; the second one is reducing vulnerability to risks, and then the third one is maintaining social cohesion, in particular by the proximity of infrastructures and services.

"The success or failure of any recovery program relies, in the end, on its capacity to satisfy the cultural needs and requirements of the people who have been victims of the catastrophe" [15]. To be effective - and cost effective - the ex-ante recovery strategy must necessarily include local population with three goals. This is a first step to ensure the adequacy of responses to the needs of victims, secondly, it is to lead civil society from receiving assistance to being a stakeholder, and lastly, the objective is to reduce conflict by promoting accession of public opinion and strengthening society identity and attachment to territory [16]. However, implementing the integration of the whole society is not obvious because it requires a structuring effort of stakeholders including civil society.

The "Participatory Planning Guide for postdisaster reconstruction" [17] offers a list of stakeholders to include in the anticipatory process: the central and local governments, risk managers, financial institutions, private sector (representatives of the sectors of the local and regional economy), NGOs and voluntary groups of citizens, local researchers and media, and a representative of the cultural field (different ethnic / religious communities), marginalised and vulnerable groups (children, women, elderly, disabled, etc.).

The speed and success of the rehabilitation and recovery depends on how policy and geography are articulated [2]. There is an implicit need to take into account the reticular functioning of societies and their territories in a multi-scalar context. Anticipating the recomposition of the territory has many uncertainties that are directly related to the dynamic nature of their constant evolution. Knowledge and control of land-use laws are two essential prerequisites. It is particularly important to know precisely the content of land management procedures in order to adapt them to local needs.

In France, research addressing those issues is scarce and recent. The document "Extreme Flooding" of INHESJ suggests, amongst other changes, to amend the "Article L 111-3 of the Town Planning Code, and overthrow the rule of law in disaster recovery. [...] If prior to the disaster, no reconstruction ban is outstanding in law, the government will have the greatest difficulty in winning acceptance of a decision prohibiting any reconstruction after disaster" [18]. The objective of this work, which is a step toward recovery anticipation, is to "facilitate and encourage the return to acceptable". The use of "return to acceptable" preferred to "return to normal" is new in French institutional vocabulary. This evolution of language elements is particularly interesting because it is combined with the notion of anticipation: this is a sign of the ongoing paradigm shift.

For legal constructions, knowledge of the demographic dynamics is directly linked to land-use regulatory documents, and subjected to a reliable and up-todate cadastre. Conversely, for illegal constructions the task is more complex. Acknowledging and quantifying their existence implies integrating them in the relocation process. These households are mostly in very precarious situations, and they cannot access decent housing by themselves. But it seems the government approach is quite different.

In the Var, the organisations encountered mentioned the situation of households in precarious situations who live in mobile homes for years, often on 
leased agricultural land. These houses, although they do not exist legally, are known by locals and they sometimes have mailboxes certifying their presence. Yet, in regulatory terms, 'cabanisation' is prohibited by the regulations governing land-use. This cabanisation is partly due to the lack of control of deeds legality. These controls should be made "voluntarily" by the agents (i.e. on denunciation), but it is difficult to take responsibility to recognise the phenomenon as it should be the State's duty (that is to say the taxpayer duty) to support these poor families to relocate. This situation is a longstanding problem in the department and matches with agricultural decline since the $1990^{\mathrm{s}}$.

\subsection{Obstacles to the development of an ex- ante strategy and weaknesses of existing plans}

Reconstruction planning has been well documented in the United States and abroad but it is not yet systematically used as a post-disaster decision tool. This limited use is linked to the fact that the approach is not operational because not articulated with other socioeconomic sectors, which nevertheless maintain interdependent relationships [13]. Another shortcoming is the difficulty to clearly demonstrate the benefits generated by this strategy. The model of the cost-benefit analysis partly answers this need to quantify the benefits of the preventive investment, but some criteria are not quantifiable such as quality of life, social equity, protection of environmental resources, or improving public health for example.

The Pre-Disaster Recovery Planning (PDRP) created in 2012 by the International Recovery Platform (IRP) is part of a proactive process to anticipate the problems of recovery and to improve - or build according to the case - the capacities of the society. This type of plan is underdeveloped because it lacks a methodological framework. This task is particularly complicated, especially since it seems impossible at this time to produce a universal plan: "IRP [...] acknowledges the fact that there is no universally correct approach to pre-disaster planning" [19]. However, experience shows a number of questions arise systematically after a disaster.

The difficulty in implementing ex-ante strategy is also linked to the shortcomings and pitfalls identified in the existing plans. Several problems are frequently encountered by ex-post recovery plans which advocated a reconstruction elsewhere and otherwise, that is to say, incorporating preventive measures [20]. The first pitfall is related to the cost of these projects. It is too important to be supported by the local government, so the national government will be obliged to finance them. This questioned the sustainability of such plans in a context of State disengagement in many developed countries. Then land legislation does not allow restructuring the private property on a large-scale, thus limiting the effectiveness of these programs. Depar- tures are voluntary and expropriations are rare. The "time" factor also plays a role in the limited effectiveness of these programs. Indeed, from the moment the plans are made and when they are approved, many private properties are already rebuilt and it is unthinkable (from a social and economic point of view) to destroy them. These plans are ambitious on paper but are actually sterile at best, dangerous at worst because they start from a false premise: the reconstruction does not start on a "zero time" established by a disaster that would have made a clean sweep of the past.

"The term "rupture" indeed implies damage but not quite disintegration, discontinuity but not quite a definitive end. Very often, the radical new knowledge that is the mark of catastrophic enters into a negotiation with the cultural logics of the past, and over time the dissonances may be resolved" [21]. This quote sums up precisely the complexity of studying the recovery process that oscillates between continuity related to the weight of legacies and, bifurcation that mark the innovations to invent the future. Anticipating recovery supposes accepting and affirming that the occurrence of the disaster is a certainty for which we cannot know the exact location, intensity, geographical extent and consequences. In fact, this implies - if the risk is unavoidable - to recognise also that strategies and risk reduction policies are as necessary as necessarily limited.

Another danger of these plans is to be heard as a right for beneficiaries and thus a set of duties for managers. Therefore, if the reconstruction does not happen as scheduled in the plan, disengagement of the stakeholders may occur [13]. In addition, too much confidence in the reconstruction plans tends to limit individual actions. Yet the ex-ante planning does not always correspond to the ex-post situation. Indeed, the conditions for reconstruction vary from its beginning to its end according to the demographic composition of the area, the rate of economic growth, the value of the currency and the collective objectives. Therefore, the proactive approach may not be sufficient to develop effective recovery strategies.

\section{Complementarity of approach- es, between ruptures and conti- nuities}

\subsection{Complementarity between anticipatory approaches and ad hoc planning}

Five "general information on post-disaster reconstruction plans" must be taken into account: 1) Several disasters may occur simultaneously or cause a "domino effect" and their respective intensities are uncertain, 2) Each disaster is related to a set of possible damages, which varies regarding the intensity of the disaster, 3) Each effect has the potential to affect a number of features of the territory and society, 4) 
Some resources can be used to treat several damages, 5) Somme resources require the implementation of other resources [14]. Therefore, two strategies are possible: on the one hand the proactive approach, which consists in anticipating, and on the other the $a d$ hoc recovery program, elaborated during post-crisis management.

Given the high degree of uncertainty of this exercise, it is necessary to develop both approaches: anticipation and ad hoc management (see figure 3). Complementarity involves the creation of bridges between the procedures for they are neither redundant nor contradictory. Adaptive planning [22] is necessary since it seems impossible to overcome the labour of ex-post adjustment by a detailed assessment to adapt the strategy to the needs and to the situation which is rapidly and constantly evolving.

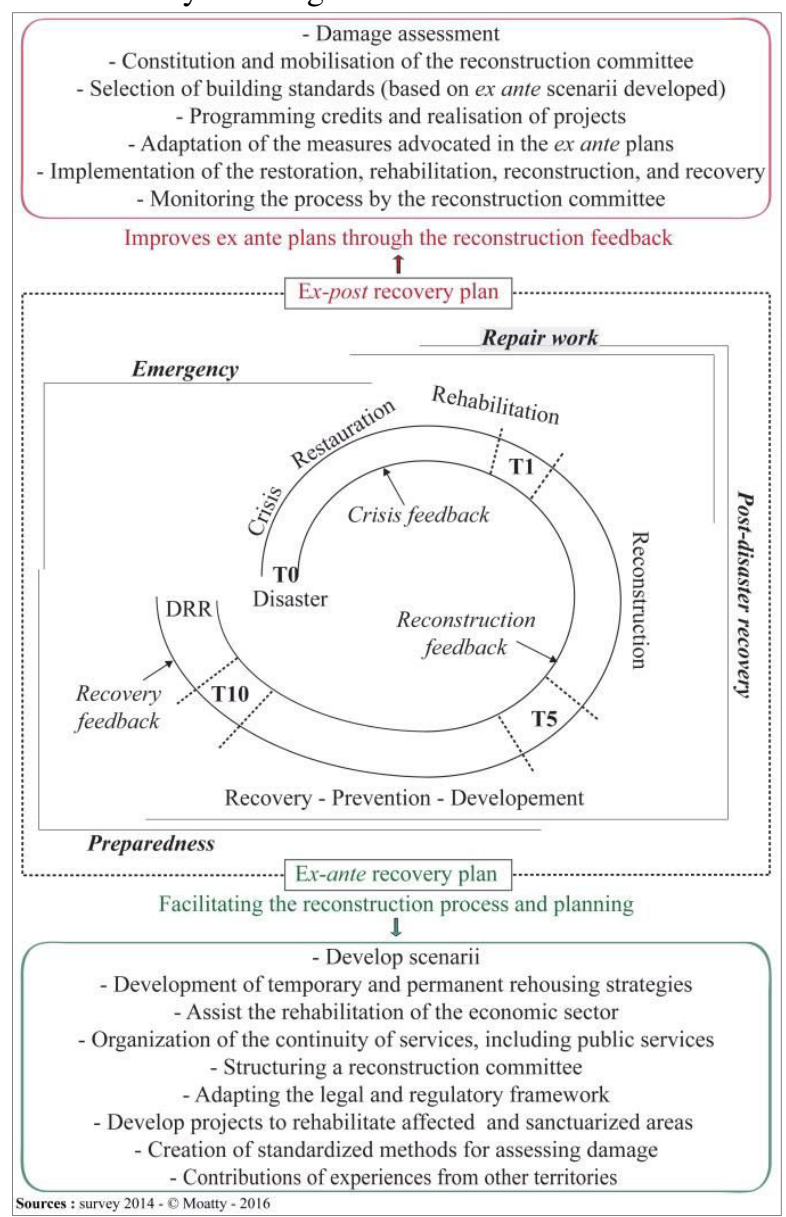

Figure 3: Virtuous cycle of reconstructions' anticipation

Anticipating the recovery means developing a management plan, and including a specific part on the actions to be implemented during the post-disaster period in existing documents. It is conceivable at first that these additions to existing plans can be made when revised in order to reduce the additional costs. The idea behind this proposal is twofold: firstly it is to replace recovery as a phase of the hazards management cycle (see figure 3 ), and thereby to accompany the paradigm shift, and secondly, to make mandatory mitigation measures that would be implemented systematically during the reconstruction.

The responses will be effective and sustainable if they are based on local resources and if they can meet the needs of the victims. Thus it is necessary to develop action plans at the municipal level to give a real power of action to this territorial level. In doing so, the government would involve more stakeholders in the process; thereby alleviate the shortage of staff available to make the connection between the central and local levels to ensure information feedback.

Citizens, organised in committees, could have the mission of giving feedback on the local empirical knowledge using standardised grids to assess needs and qualities and flaws of the plans. This data should be centralised by prefectures in order to guide decision makers, and to provide summaries to the competent ministries (interior, environment and sustainable development, housing). This organisation requires efforts for consultation and substantial training at the start but will eventually lead to a better distribution of roles and sharing of responsibilities. By delegating that kind of task, some work time of State services officers could be liberated - time that could be used to perform legality checks, and to ensure the respect of the aid conditionality and thus, ensure the respect of the prevention strategy.

If the anticipation of the recovery seems to help achieve the objectives of prevention and sustainability more easily and quickly, it must necessarily be complemented by ex-post plans to adjust the strategy since it is impossible to know precisely the extent of the situation after the disaster. The ability to create ad hoc structures should not be suppressed by the planning effort. Therefore the two approaches are complementary, each aimed at reducing the gaps of the other. However, these gaps cannot be completely eliminated because management policies "necessarily produce undesired, unexpected effects" [23], adding uncertainties that makes decisions even more complex.

\subsection{Relying on local "good practices" - the example of Interministerial Recovery Unit (IRU)}

"Good practices" had been noticed on the recovery process of the Aude and the Var department. Regarding the previous finding, the structuration of the stakeholders is a key issue and the experience of both departments might be reported as a "good practice" in that field.

Developing ex-ante strategy establishes a habit of working together for managers and decision makers. Thereby the implementation of the action plan would be facilitated. The PDRP stipulates that it is necessary to create an organisational structure that assigns roles and responsibilities. The distribution of roles is done through ad hoc structures composed of reconstruction 
management committees, which are in France mostly programming committees.

In this field, an adaptation of the IRU can be imagined, which was set up in Aude after the 1999 floods and in the Var after those of 2010. IRU missions aim to raise funds, to maintain the organisational plan, to communicate on the contents of the strategy, to ensure the update of the programming and action plan regarding the risk and damage assessment, to develop specialised teams by major reconstruction issues, to use the internal resources for the society, to anticipate and take into account the arrival of donations in order to establish a transparent management, and to support a leader well identified by the population who will be in charge of the communication task.

The existing financial procedures need to be mobilised quickly and the chain of decision-making must be simplified to meet this need for speed. The IRU which acts as a single window enables simplification while ensuring control level over the management of public funds.

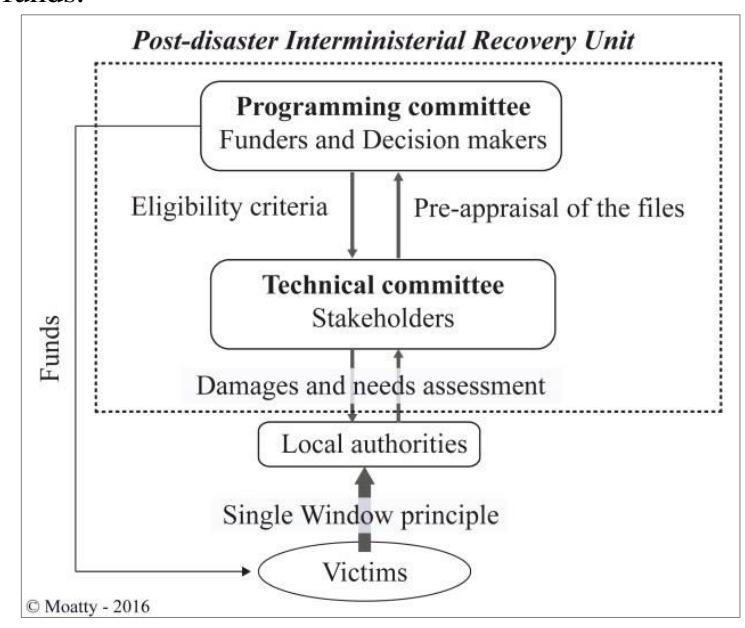

Figure 4 : The Post-disaster Interministerial Recovery Unit

RIU (see figure 4) is controlled by the Prefect who is a well-identified leader by all the partners. The technical and the programming committees, by their composition, involve local stakeholders who are best able to adapt measures to the specific characteristics of the society. This approach has the advantage of not opposing the institutional approach, called "top-down", and the participatory one, called "bottom-up". Even though the victims are not directly involved in the decision-making process. Their relation to decision makers is limited to a consultative role. Indeed, in this system the local authorities and organisations relay the needs and expectations of people.

The programming committee examining the cases that were presented by the technical committee who constituted "recovery grant folders" with the victims and bringing additional expertise in pre assessed favourable or unfavourable opinion to grant applications. A project manager was appointed to coordinate the different processes and send progress reports to the ministry.

This gathering of funders, policy makers and managers within the same structure helped them to build a shared culture of recovery and common technical tools. The mission effectiveness was proven by its readaptation in the Gard department following the 2002 floods, or following the storm Xynthia in 2010, for example. This type of reconstruction committee can also be found abroad: the Mount Pinatubo Commission established after the eruption and lahars of June 1991 [4], the reconstruction commission after the Kobe earthquake in 1995, or that of Sendai city and more broadly of the Tohoku province after the Great East Japan Earthquake and tsunami in March 2011, in Japan.

To coordinate their activities, the stakeholders should have a common language [24]. The construction of this reference language that makes consensus is part of collaborative efforts that must be initiated ex-ante to have more chances of success. If the mechanisms and tools are known and apprehended in quiet time, they will be more easily mobilised during reconstruction. During our investigations, respondents also mentioned an improvement of labour relations after reconstruction. Indeed, $47 \%$ of respondents suggest that the relationship between institutions and stakeholders were more frequent, more effective and simpler. The management of following cases became easier for a large majority of the stakeholders $(79 \%)$.

In the Aude department, as in the Var, this clustering dynamic was rooted in the long term through the development of sustainable management structures: the Joint Association of Aquatic Environments and Rivers (created on 30.05.2002) in the Aude and the Joint Association of Argens (created on 02/03/2014) in the Var. Those structures were elaborated on the model of the IRU. The effort promoted during the reconstruction is perpetuated, indicating that this mode of governance put in place ad hoc works well and can be adapted to fit the land-use development in the long term.

\section{Conclusion}

The purpose of anticipation is to develop medium and long term projects built on participatory methods (with strong leadership) around which all the stakeholders are gathered (although the consensus remains utopian regarding conflicting interests) to match the general interest defined collectively to give weight to the decisions along the lines of "preventive ethics". To cope with it, the notion of disaster must enter the field of possibilities and must be understood both as an external element which must be mitigated as a component of the life of the territories produced by the societies in the long time. 
Anticipating reconstructions shows many advantages. The main one is to bring land-use stakeholders to collectively reflect on the development of the territory and shifting what can be shifted in reconstruction period. It is not possible to anticipate everything. A multitude of uncertainties and contingencies will be managed by the creation or adaptation of structures and management tools ad hoc. Indeed, it is impossible to predict with certainty the total damage and potential "domino effect" that can occur during crisis and immediate post-crisis. The use of graduated responses scenarios based on the risk scenarios (depending on the intensity, the extension of damages, and the nature, more or less strategic, of the assets, etc.) would partially mitigate these uncertainties.

The strategic orientation of documents resulting from this anticipation must have some flexibility to allow adaptation; otherwise they might be counterproductive. As such, it is necessary to operate a "desectorialisation" of the fields of risk management, and widely of land-use planning. The concept of historical bifurcation questions the development path of the territories and the societies. It challenges choices that seemed "set in stone" for eternity without excluding the past.

The evaluation of the anticipatory strategies of recovery is also a major issue. The comparison of indicators measured before and after the disasters and recovery can bring some answers. But then how to distinguish changes caused by the disaster and the choices made during reconstruction of those that would have occurred anyway? If using data such as population return rate, how to distinguish those who were unable to return from those who do not want to come back? How to measure the weight of reconstruction strategies in this choice to uproot?

The solution appears to reside partly in the completion of a detailed case-by-case analysis. But it is clear this data collection method is flawed: it is long and expensive, it will always include biases related to the first highly subjective nature of responses that can be made by those concerned, and then by the biases linked to the personal characteristics of agents who are analysing such information, although they use rigorous methodology. The weight of the interpretation and the factors influencing this process exposes the information thus produced to controversy. But confrontation with controversy cannot be totally negative, it is certainly a vector of blockages and delays, but may in the long term lead to changes and adaptations to better integrate different interests and to better represent society as a whole.

\section{References}

1. OXFAM (2009). Le droit de survivre, le défi humanitaire du $21^{\text {ème }}$ siècle, $8 \mathrm{p}$.

2. Alexander D. (2010). Post disaster reconstruction: planning and sustainability, University of Florence, $35 \mathrm{p}$.

3. Christoplos I. (2006). The elusive "window of opportunity" for risk reduction in post-disaster recovery, Intervention "ProVention Consortium Forum”, Bangkok, 2-3 February 2006, 4p.

4. Gaillard J. C. (2008). Alternative paradigms of volcanic risk perception: The case of Mt. Pinatubo in the Philippines. Journal of Volcanology and Geothermal Research, vol. 172, $n^{\circ} 3-4$, pp. 315328.

5. Vinet F. (2003). Crues et inondations dans la France méditerranéenne. Les crues torrentielles des 12 et 13 novembre 1999 (Aude, Tarn, Pyrénées Orientales et Hérault), Editions du Temps, Nantes, 224 p.

6. Ingram J. C., Franco G., Rumbaitis-Del Rio C. and Khazai B. (2006). Post-disaster recovery dilemmas : challenges in balancing short-term and long-term needs for vulnerability reduction, Environmental Science \& Policy, 9, pp. 607-613.

7. Hernandez J. (2009). The Long Way Home : une catastrophe qui se prolonge à La NouvelleOrléans, trois ans après le passage de l'ouragan Katrina, L'Espace géographique 2009/2, Vol. 38, pp. 124-138.

8. Disaster Mitigation Act (2000). Public law 106390, OCT. 30. FEMA, 26 p.

9. Mc Entire D. (2007). Disaster Response and Recovery. Hoboken, NJ : Wiley, c2007. 498 p

10. Olshansky R. B., Hopkins L. D., Johnson L. A. (2012). Disaster and recovery: processes compressed in time. Natural Hazards Review, 13, 3, 173-245.

11. Dumas P., Chavrot A., Legrand H., Macaire A., Dimitrov C., Martin X. and Queffelec C. (2005). Mission d'enquête sur le régime d'indemnisation des victimes de catastrophes naturelles. $756 \mathrm{p}$.

12. Palier J. and Prevost B., (2007). Vulnérabilité et gestion des risques : potentialités et limites de la microfinance. L'exemple de l'Inde du Sud, Mondes en développement, $\boldsymbol{n}^{\circ}$ 138, pp.103-118.

13. Smith G. and Wenger D. (2006). Sustainable disaster recovery: Operationalizing an existing framework in Rodriguez H., Quarantelli E. and Dynes R. (Eds.), Handbook of disaster research, New York: Springer, pp. 234-257.

14. Bryson K. M., et al. (2002). Using formal MS/OR modeling to support disaster recovery planning, European Journal of Operational Research 141 in Elsevier, 10 p.

15. Aysan Y. and Oliver P. (1987). Housing and culture after earthquakes. Oxford, Oxford Polytechnic Press. 
16. De Vanssay B. (2010). Le Reconstruction - Développement Durable et Réduction de la Vulnérabilité, Risques Infos $\boldsymbol{n}^{\circ} \mathbf{2 4}$ (publication de l'Institut des Risques MAjeurs), pp.6-9.

17. Participatory Planning Guide for Post-Disaster Reconstruction (2004). Join report prepared by EPC-Environmental Planning Collaborative, Ahmedabad, India and TCG International, LLC, Washington DC with the support of USAID/India and the Indo-US Financial Institutions Reform and Expansion (FIRE-D) Project, January 2004, $26 \mathrm{p}$.

18. Schott C., (dir.) (2014). Inondation extrême quelles réponses à l'échelle nationale et européenne. Rapport du Groupe de diagnostic stratégique $n^{\circ} 1-25 e$ Session nationale "Sécurité et Justice »-2013/2014. INHESJ, 68 p.

19. IRP, UNISDR (2012). Guidance note on recovery: pre-disaster recovery planning, $45 \mathrm{p}$.

20. Diefendorf J. M. (2009). Reconstructing Devastated Cities: Europe after World War II and New Orleans after Katrina, Journal of Urban Design, 14:3, 377-397.

21. Gray P. O. and Kendrick O. (2004). The memory of Catastrophe, Manchester - New York, Manchester University Press, $50 \mathrm{p}$.

22. Smith G. P. (2004). Holistic Disaster Recovery: Creating a More Sustainable Future, Online Training, Federal Emergency Management Agency, (November 1, 2009).

23. Pigeon P. (2010). Catastrophes dites naturelles, risques et développement durable : Utilisations géographiques de la courbe de Farmer, VertigO la revue électronique en sciences de l'environnement [En ligne], Volume 10 Numéro 1 | avril 2010, mis en ligne le 26 avril 2010, consulté le 08 octobre $2015 . \quad$ URL http://vertigo.revues.org/9491 ; DOI : 10.4000/vertigo. 9491

24. Coles J. B. et al. (2011). Case study in disaster relief: A descriptive analysis of agency partnerships in the aftermath of the January 12th, 2010 Haitian earthquake, Socio-Economic Planning Sciences in Elsevier, p.11 